\title{
EXAMEN DE CRÍTICA. EXAMEN DE CRÍTICOS
}

Referirme, como aquí me refiero, a la crítica literaria —con breves alusiones a otros géneros de crítica artística-r requiere, por el hecho mismo de este referir, una aclaración previa. Un examen de la crítica (y de los críticos) es, de por sí, un lenguaje de tercer grado. En efecto: está el lenguaje de la obra - poema, cuento, novela, teatro-; está el lenguaje del crítico acerca de la obra; ahora resulta que aparece un tercer lenguaje acerca del lenguaje crítico mismo. ${ }^{2}$ Este lenguaje tercio o tercero se presenta, además, en varias perspectivas: constituye a veces un lenguaje descriptivo en cuanto narra los métodos empleados por los críticos y, en este sentido, es un lenguaje informativo; pero es también, en cuanto juzgamos -invitablemente- del valor o desvalor o valor a medias de los distintos métodos críticos, un lenguaje que enjuicia, es decir, también un lenguaje crítico; es, por fin, en cuanto trata de proponer esquemáticamente un punto de vista crítico —el que pienso más adecuado-, un lenguaje al mismo tiempo valorativo, electivo, estimativo y selectivo. Advertirá el lector que, en las páginas que siguen utilizo tres planos expresivos que pueden escuetamente reducirse a tres palabras: descripción, valoración, proyecto. Descripción, efectivamente, de métodos; valoración de estos mismos métodos; proyecto de una opinión y una posición más o menos personal acerca de la crítica. De ahí el plan de este examen. Examinaré, en primer lugar, los sentidos que tiene la palabra crítica; explicaré, algo más detalladamente, las distintas formas, o si se quiere, los distintos géneros literarios y distintas aproximaciones metódicas que emplean los críticos; esbozaré algunas ideas sobre la crítica que provienen tanto del análisis de las escuelas que la practican como de mi propia experiencia crítica.

Es necesario buscar aquí sentidos y significados históricamente varios y variables de la palabra "crítica". En forma sencilla, también clara, escribe

1 Mi examen se reduce al de la crítica literaria, y aun no a toda ella, en el siglo xx. Breves excursiones a la crítica del pasado serán a veces necesarias. Renuncio, salvo muy pocas excepciones, a examinar otros tipos de crítica artística, porque los problemas que plantean - por ejemplo, el de la traducción de lenguajes no verbales a un tipo de lenguaje verbal- sobrepasan con mucho el límite de un ensayo. Además, desde que empezó a emplearse en Grecia la palabra criticós, ésta se refería al enjuiciador de lo que hoy llamamos literatura. Inicialmente la crítica fue literaria. (Véase René Welleck, Concepts of Criticism, Yale University Press, 1963).

$2 \mathrm{Mi}$ lenguaje llega a ser "cuaternario" cuando examino teorías que analizan la teoría literaria la cual, a su vez, se referiría a la "crítica" y ésta, a la "obra".

[200] 
Roque Barcia (Sinónimos castellanos): "Crítica viene de crisis, que significa cambio o mudanza". Escribe también: "La palabra krisis quería decir entre los griegos combate, lucha, esfuerzo, juicio, como derivada de krino, que equivalía a juzgar o distinguir". A partir de este significado original, todavía presente en la crítica de nuestros días, la palabrà crítica ha pasado a signií ficar, en el lenguaje común, censura, ataque o incluso chisme -un "criticón" puede ser un chismoso-; en el lenguaje de las ciencias, "espíritu crítico", es decir, espíritu tanto dubitativo como analítico; en el lenguaje de la moral y de la estética, "discernimiento" - así, cuando Alfonso Reyes titula $E l$ deslinde a una de sus grandes obras de crítica y ciencia literaria, de hecho lo está titulando "crítica", por lo menos en uno de los sentidos de esta palabra.

Por otra parte, cuando hablamos de crítica literaria podemos referirnos a distintas modalidades críticas: valorativas, estimativas, enjuiciadoras, normativas, polémicas, descriptivas, sintomáticas, etc. Algunos críticos piensain acaso practicar un solo tipo de crítica. Me parece que de hecho, explícitamente o no, practican varios. Malherbe y Boileau pretendían dar reglas literarias y su crítica fue, principalmente, normativa. En ninguno de los dos casos dejó de ser estimativa, enjuiciadora y aun polémica, sin olvidar hasta qué punto estuvo llena de juicios morales y aun "filosóficos". ${ }^{3}$ André Breton practicó una crítica polémica y programática - la del primer Manifiesto del surrealismo-; practicó también una crítica psicológica, cuasi psicoanalítica, metafísica y de proyecciones poético-filosóficas (así: la unidad de los opuestos en el inconsciente creador del poeta). Las dịstintas modalidades críticas son contagiosas y no creo que exista un solo caso de crítica que se realice "en pureza", salvo, tal vez, la que realizan algunos historiadores de la literatura cuando quieren fijar una fecha precisa o un tejido de relaciones cronológicas.

En suma, la crítica puede presentarse, fundamentalmente, bajo tres especies: y ello tanto si se juzga la obra, el autor, el lector como si se pretende juzgar a los tres; crítica normativa - predominante en el arte clásico europeo y en las letras clásicas de Europa, a partir de Castelvetro; crítica interpretativa - por ejemplo, en los casos de la crítica psicoanalítica y en ciertos casos de crítica sociológica; crítica descriptiva - principalmente en los métodos fenomenológico y estilístico. En todas sus especies, la crítica, aun cuando lo nieguen sus autores, está teñida de juicios apreciativos, estimativos y valorativos. Esto - habremos de verlo-- porque toda crítica parte de cierta idea de la literatura, idea que, por su lado, arraiga, conscientemente o no, en lo que provisionalmente llamaré una visión del mundo. También los críticos parecen haber nacido platónicos o aristotélicos.

3 Importa señalar los muchos puntos de confluencia - no de influencia - entre Boileau y Descartes y entre ambos y Poussin. 
He querido consignar, hasta aquí, algunos sentidos de la palabra crítica y he tratado de mostrar cómo estos sentidos diversos se encuentran en un mismo autor. Paso ahora a reseñar las principales tendencias críticas de nuestro siglo y, cuando ello me parece necesario, a criticarlas.

\section{Critica psicoanalitica. Ciencia literaria}

Dos tendencias de la crítica contemporánea pretenden ser cientificas. Una, la crítica psicoanalítica, por fundarse en los descubrimientos de esta ciencia no carente de arte que llamamos psicoanálisis; la otra porque trata de hacer de la crítica misma una ciencia y quiere así llamarse a sí misma ciencia literaria.

El psicoanálisis - habría que decir, con más exactitud, los psicoanálisisha tenido una repercusión de todos sabida y conocida en el mundo moderno. Escritores, pintores, artistas, novelistas, sociólogos, poetas, no piensan después de Freud, y especialmente después de los análisis que Freud dedicó a los sueños, como pensaban antes de que Freud escribiera. Ciertamente, la idea de un inconsciente en el cual se encuentra la expresión más auténtica de la vida humana fue una de las principales preocupaciones de los románticos y, en especial, de los románticos alemanes (Moritz, Lichtemberg, Novalis) y de los simbolistas franceses (Rimbaud, Lautréamont). Es larga la búsqueda de lo real más allá de lo aparente - tan larga como la historia del pensamiento. Pero la influencia freudiana en letras y artes ha sido y sigue siendo decisiva. Surrealismo, escritura automática, espontaneidad creadora, expresión erótica, sueños convertidos en poesía y poesía soñada son "temas de nuestro tiempo". No es que Freud haya influido directamente en la literatura de nuestro tiempo. Muchas veces los escritores que más quieren acercarse al psicoanálisis más se alejan de él. Muchas veces la influencia de Freud rebasa los límites de la doctrina freudiana y muchas veces llega a negarla. Sean cuales fueren las relaciones entre la psicología de Freud y sus resultados literarios, la presencia del psicoanálisis en la literatura es indudable.

La crítica psicoanalítica empieza con Freud mismo. Habian de proseguirla psicoanalistas y críticos.

Las "lecturas" artísticas de Freud -entre ellas, la más importante es la que dedica a Leonardo da Vinci- tienden, a pesar de que Freud mismo niega la posibilidad de psicoanalizar a autores cuya historia es remota y cuyo interrogatorio es claramente imposible, a constituirse en lectura sintomática. Más que crítica artística, Freud realiza un análisis del artista para compararlo y deslindarlo del neurótico. Más cercano a la obra de arte, Otto Rank lleva a cabo análisis de primer orden tanto de la personalidad artística 
como de los mitos y, especialmente, el mito del héroe. Algunas veces Rank intuye la vida del artista: no es dudoso que el artista tenga un afán muy señalado de inmortalidad. Es, en cambio, dudoso, que proceda por miedo morboso a la muerte o - hipótesis central en la obra de Rank- que el artista sea bisexual. En algunos casos Rank se acerca mucho a entender el artista; en otros sigue, como Freud, realizando lecturas clínico-sintomáticas.

Más cercanos a la obra de arte: Jung y Fromm. Ninguno de los dos pretende ser crítico. Ambos, como en general todos los psicoanalistas, tienden a colocarse en la perspectiva del creador. Ambos coinciden en pensar, contrariamente a Freud, que los sueños pueden ser creadores y, en la obra de Fromm, no sólo creadores sino también racionales. El sueño puede ser así forma de la creatividad y del descubrimiento. Jung y Fromm, tan distintos y aun tan opuestos, en sus métodos e hipótesis coinciden con Bergson al mostrar la creatividad de la conciencia onírica. Pero ni Jung ni Fromm llevan a cabo análisis estéticos o artísticos.

Jung distingue claramente entre dos formas de la creación artística y, especialmente, poética: la forma psicológica y la visionaria. La visión del artista no puede reducirse a la primera y, por lo tanto, la lectura que Jung propone de la poesía no es clínica como lo fue la de Freud. La visión del artista revela, según Jung, la presencia del inconsciente colectivo. Escribe: "No es Goethe quien hace el Fausto, sino el Fausto el que hace a Goethe." 4 Jung entiende el papel del poeta pero, en última instancia, la obra poética remite a la teoría psicoanalítica de Jung y sus lecturas, tanto de la poesía alemana como del libro de los muertos del Tibet, le conducen a reafirmar su propia hipótesis psicológica: la de un inconsciente colectivo cuyos arquetipos pueden "leerse" a través de los símbolos que los representan. ${ }^{5}$

Si los psicoanalistas no han llevado a cabo una verdadera labor crítica -que por lo demás no les correspondía-, sus ideas han influido parcial o totalmente a excelentes críticos modernos. Menciono, entre otros, a Kenneth Burke cuya Grammar of Motives propone el desarrollo de una "simbólica" capaz de analizar los motivos y las motivaciones de la creación artística. Burke, sin embargo, no se limita a utilizar métodos estrictamente freudianos ni estrictamente psicoanalíticos. Acepta que los mecanismos de los sueños (condensación, dramatización, holotimia, etc.) constituyen la esencia de la poesía, de la "poesía como sueño". Sin embargo, modifica el método freudiano y lo amplía cuando afirma: "Diría, para los fines explícitos de la crítica literaria, que debemos destacar, en cuanto lo permite, la estructura

4 C. G. Jung, Psicología y poesia, en Filosofia de la ciencia literaria, Fondo de Cultura Económica, México, 1946.

5 Dos observaciones. Recientemente Lévi-Strauss supone la existencia de un inconsciente "lógico" y, en este sentido, racional. Por otra parte, la lectura "arquetípica" tiene claros y riquísimos antecedentes (más ricos que sus consecuencias actuales), en la Ciencia Nueva de Vico. 
freudiana: 1) la estrategia proporcional en oposición a la estrategia esencia, lizante; 2) las simbolizaciones matriarcales contra el prejuicio: patriarcal de Freud; 3) el poema como oración y como mapa en oposición a la idea del poema como un simple sueño" (The Philosophy of Literature). Burke, además, adopta métodos de la Gestalt, del conductismo y, más generalmente, de las diversas tendencias psicológicas actuales. Excelente crítico de Nietzsche, D. H. Lawrence, Coleridge, Burke es acaso mejor en su crítica cuando sigue su propia intuición y su sentido artístico que cuando se limita en exceso al método de análisis que propone.

También crítica psicológica y especialmente psicoanalítica es Maude Bodkin, de quien ha dicho S. E. Hyman (The Armed Vision) que no es psicóloga profesional ni crítica profesional. Maude Bodkin demuestra en su obra algo más que profesionalismo: verdadera penetración y comprensión de la obra. Poco éxito tuvo en un principio Archetypal Patterns in Poetry, cuando se publicó en Inglaterra. Sin embargo, Maude Bodkin ha realizado los mejores análisis propiamente psicoanalíticos en la esfera de la poesía. Fundándose en el psicoanálisis jungiano, sin olvidar otras tendencias psicológicas, Maude Bodkin desarrolla una de las hipótesis de Jung: la hipótesis según la cual la poesía refleja símbolos que provienen del inconsciente colectivo. En este sentido analiza la imagen femenina en el Paraiso perdido de Milton o la oposición de los arquetipos cuerpo-alma en la obra de D. H. Lawrence. ${ }^{6}$ Gran virtud de Maude Bodkin: no sucumbir en una lectura clínica y saber que el análisis psicoanalítico es importante y también insuficiente. Lo que cuenta, en última instancia, y en las palabras de la crítica inglesa, es "el goce de la belleza de la poesía".

Entre los críticos que han utilizado los métodos psicoanalíticos deben mencionarse: Herbert Read, Lionel Trilling, Edmund Wilson-cuya obra monumental sobrepasa con mucho los marcos de una escuela-, Mark van Doren y, en alguna ocasión, I. A. Richards, aunque éste sea sobre todo el más agudo crítico de otra escuela a la cual nos referiremos más adelante: el "New Criticism".

Los críticos que se inspiran en el psicoanálisis pretenden parcialmente fundar una crítica científica. La que se ha llamado "ciencia literaria" pretende en cambio fundar una crítica científica.

Muchos han dudado del valor de la ciencia literaria. Entre ellos, Guillermo de Torre cuando señala la imposibilidad de reducir el estudio de las letras (o las artes) a ciencia. Voy de acuerdo con estas dudas. En primer lugar, porque el estudio de la ciencia literaria nos muestra que no existe una sola y única ciencia de la literatura -en el sentido en que existen una "física"

6 Octavio $\mathrm{Paz}$ ha analizado, de manera semejante, las múltiples relaciones entre el cuerpo y el no-cuerpo (Conjunciones y disyunciones). Las ideas de Paz, muy originales, se relacionan, sin embargo, y de manera relativamente directa con las de Norman O. Brown y también las de Mauss y de Lévi-Strauss. 
o una "química". La ciencia literaria parece padecer de una enfermedad incurable si de veras quiere ser una ciencia: la de la multiplicidad.

$\mathrm{Si}$ una disciplina debe convertirse en ciencia tiene que establecer un sistema de leyes a partir de las cuales puedan explicarse los hechos. A tratar de establecer leyes de la ciencia literaria dedica Emil Ermatinger su ensayo La ley en la ciencia literaria (Filosofía de la ciencia literaria, Fondo de Cultura Económica). Apunta Ermatinger que el concepto de ley natural es relativamente reciente. El sentido primordial de ley (nomos, lex) connota legislación de orden teológico-moral. Si la ciencia literaria, como en general las ciencias humanas, tiene que buscar leyes para su propio campo de reflexión, éstas deben ser leyes no mecanicistas y no cuantitativas. Suponiendo que la ciencia es esencialmente "actividad legisladora" — suposición que aproxima el pensar de Ermatinger tanto a Kant como a Dilthey-, hay que suponer también que existen dos tipos de legislación: la que se refiere al mundo de los objetos naturales y la que se refiere, no sólo en forma distinta sino aun "antagónica", al "mundo espiritual". En este segundo caso las leyes tendrán un carácter individualizante. Así Ermatinger se opone a los métodos inductivos del positivismo y de una crítica literaria que estuvo excesivamente influida por la ciencia natural.

Una vez establecida la necesidad de dar leyes para el estudio de la literatura, Ermatinger sugiere que éstas deben ser: 1) leyes generales; 2) leyes especificamente relacionadas a tres problemas precisos: el de la historia social, el de la "personalidad poética en el aspecto psíquico de la concepción del mundo y de su desarrollo", el del "análisis de la obra de arte poética". En suma: se trata de ir al encuentro de leyes universales y necesarias que determinen "la individualidad literaria". Las cuatro leyes son: "la ley de la unidad de sentido como conexión teleológica implícita en el concepto de la individualidad histórica"; la "ley de la relación entre lo típico y lo singular como acuñación precaria, lábil, de Io individual"; la "ley de la polaridad, como despliegue de una unidad de vida en la dualidad antagónica de las fuerzas en acción, distinta de la antítesis cuantitativa en sentido matemático"; la "ley de la continuidad".

Ermatinger aplica las cuatro leyes a los que considera tres grandes problemas de la ciencia literaria: la comunidad que estudia la ciencia de la literatura; la personalidad poética; la obra de arte. Es decir, las letras desde tres puntos de vista complementarios: la sociedad, el autor, la obra. Resumo algunas aplicaciones en las cuales estas leyes adquieren contenido y valor.

Relacionada a la personalidad del poeta la ley de la "unidad de sentido" significa triplemente "unidad fisiológica", "unidad psicológica", "unidad de vivencia". La personalidad poética constituye así, para Ermatinger, como para su lejano y cercano maestro Dilthey, "unidad concreta de vida". Por lo que se refiere a la relación entre lo genérico y lo singular, piensa Ermatinger que 
la personalidad general del poeta se revela en datos singulares y concretos, "en un solo rasgo, en un determinado gesto". La polaridad, referida una vez más a la personalidad del poeta, es de orden anímico-espiritual y puede presentarse, por ejemplo, como "un contrajuego... entre valores metafísicos, psicológicos y morales". Cuando este contrajuego de oposiciones vitales y anímicas se acentúa en exceso, la personalidad poética puede estancarse. Finalmente, la ley de la continuidad suele regir, para decirlo con Ermatinger en palabras de Goethe, como "diástole y sístole del inspirar y del expirar en el proceso de la vida".

¿Ciencia de la literatura? ¿Arte del crítico? Ambas cosas. Escribe Ermatinger: “. . será una obra ideal de ciencia literaria aquella en que una personalidad sea capaz de exponer una materia aceptada certeramente y a fondo con absoluta claridad en lo tocante a las leyes lógicas de su ciencia y en un lenguaje artísticamente modelado y vivo".

La actitud de Ermatinger cobra sentido cuando se entiende como una clara reacción contra las tendencias cientistas del positivismo. Su noción de ley literaria pretende ser universal sin tener que limitarse a la universalidad de las ciencias naturales o de la matemática. Dos ideas subrayan el método de Ermatinger, ambas de raíz y origen diltheyano: la obra de arte, que sigue reglas estrictas, es obra de vida; así, la obra de arte podrá entenderse cuando entendamos y conozcamos el proyecto de vida del poeta y la concepción del mundo que entraña este proyecto de vida.

El método que propone Ermatinger es riguroso, preciso y útil. Sin embargo, no queda del todo claro en qué sentido una ley puede seguir llamándose ley y ser, al mismo tiempo, lenguaje particular referido a obras y creaciones particulares. La ciencia literaria que propone Ermatinger se asemeja a la que, expresando ideas de Dilthey, se llamó una vez "psicología de las situaciones vitales". Pero esta psicología o lo es en serio como intento de ciencia (y se llama entonces psicoanálisis o se llama conductismo) o, probablemente, deja de ser una ciencia para convertirse en una suerte de literatura abstracta acerca de la literatura, una psicología abstracta acerca de la psicología.

\section{Critica fenomenológica}

Ninguno de los fundadores de la fenomenología se dedicó a la crítica literaria. Sólo desde un punto de vista existencial se han dedicado a ella Sartre o Merleau-Ponty. Pero la crítica de Sartre está al servicio de su moral social y de la de Merleau-Ponty, espléndida como es, es más parte de su propia filosofía que crítica explícita.

En el campo estricto de la crítica literaria algunos se fundaron en el método fenomenológico. Tal es el caso de Roman Ingarten quien, aun cuando 
parte de métodos descriptivos, anuncia y en buena parte crea métodos formalistas que están ligados a análisis estructural más que a la fenomenología propiamente dicha. Más cercano a un método fenomenológico, es el que emplea Alfonso Reyes en uno de los grandes libros que sobre el tema se han publicado en castellano: El deslinde. Reyes intenta en su libro, mediante un proceso descriptivo, eliminatorio y comparativo, mostrar qué es "lo literario": esencia de la literatura a la cual se llega por suerte de "vía negativa", por una descripción precisa de aquello que la literatura no es o de aquello que es literario solamente bajo forma "ancilar". Pero Alfonso Reyes no quiso nunca limitarse a una metodología crítica cerrada. Practicó la crítica histórica como muy pocos en nuestra lengua; practicó muchas veces la crítica estilística, la crítica filológica, la crítica sociológica... La actitud de Reyes, esencialmente antidogmática, queda claramente definida en el párrafo inicial de Tres puntos de exegética literaria: "La crítica va desde la libre impresión humana hasta el alto juicio que sitúa las obras en los cuadros de la cultura. En la zona intermedia de estos dos extremos, hay aquella cuesta de laborioso acceso que admite la aplicación de métodos específicos y que se reduce a la labor exegética. Tales métodos se encierran en tres: el histórico, el psicológico y el estilístico. Sólo la integración de los métodos puede aspirar a la categoría de Ciencia de la Literatura, aunque los partidarios exclusivos de uno u otro reclamen para su orden preferido el nombre de ciencia, y aunque en la práctica, y al estudiar las obras determinadas, realmente echen mano de los tres métodos." Tal es la intención de Alfonso Reyes. Tal, también, su realización, su crítica es una de las que más se aproximan a una crítica plena y completa. ${ }^{7}$

Originalísimo y de difícil clasificación es el método que ha empleado Gaston Bachelard. Bachelard, filósofo de la ciencia que prescinde de las ideas geométrico-mecanicistas sin por ello prescindir de la razón, se encuentra múltiplemente con la obra literaria y, específicamente, poética. Pocos libros tan ricos de sugerencias como su Lautréamont, su Psicoanálisis del fuego, El agua y los sueños, El aire y los sueños, La tierra y los sueños de la voluntad, La llama de una vela, La poética del ensueño. El método de Bachelard recuerda a veces el de los psicoanalistas pero se separa de ellos, en primer lugar, por analizar mucho más los ensueños (songes, rêveries), que los sueños y, en segundo lugar, porque Bachelard intenta una reflexión sobre los arquetipos imaginarios. Bachelard busca, en efecto, el sentido poético de los cuatro elementos en la obra poética, rechaza "el plano de la historia" y hace resaltar "la sorda permanencia" de los elementos. Dos tipos de objetividad: la del espíritu científico "para el cual la antipatía previa es una sana precaución"

7 Interesa notar que el intento de Reyes por aislar el hecho literario coincide - sin influencias aparentes - con Ia tentativa de los formalistas rusos de Poetika - entre ellos Roman Jakobson. Sin embargo, Reyes realiza su intento dentro de una tendencia critica más descriptiva $-y$ en este sentido fenomenológica_, que formalista. 
y el espíritu poético, de orden "expansivo". El primero requiere un género de objetividad que rompe con la objetividad cotidiana y de término medio; el segundo acepta un fenómeno dado en la vida, dado en el poema -agua, aire, tierra, fuego- que nunca alcanza a ser objeto y que conduce "al poético redil donde los sueños sustituyen al pensamiento y donde los poemas ocultan a los teoremas" (Psicoanálisis del fuego). ¿Escisión de la conciencia en conciencia científica y conciencia poética? No del todo. Escribe Bachelard: "Creemos que todo lo que es específicamente humano en el hombre es logos. No llegamos a meditar en una región que estuviera situada antes del lenguaje" (La poética del espacio).

\section{Estilistica}

La estilística ha constituido y sigue constituyendo uno de los métodos más exactos del análisis literario en los siglos xIx y xx. Sin embargo, no es fácil hablar unitariamente de la estilística; varios son sus métodos y varias sus hipótesis. Veamos primero aquello que las diversas formas de la estilística tienen en común.

La estilística es - lo dice la palabra misma-- un análisis del estilo, de la manera de escribir y de la escritura. Pero si la estilística se redujera a este triple análisis poco tendría de novedad. Cuando los sofistas y después Aristóteles fundan y afinan la retórica, estudian ya en ella las modalidades y las formas de la escritura, aun cuando su finalidad sea la de alcanzar un alto grado de persuasión. La retórica antigua y clásica estudia el estilo tanto desde el punto de vista de quien habla como desde el punto de vista de lo que la obra expresa. Paul Valéry hacía notar la importancia del análisis de tropos y figuras -ambos propios de la retórica- y escribía: "estas figuras, tan abandonadas por la crítica de los modernos, representan un papel de primera importancia, no sólo en la poesía declarada y organizada, sino también en esta poesía perpetuamente activa que atormenta el vocabulario fijo, amplía - limita el sentido de las palabras, altera constantemente los valores de esta moneda fiduciaria" (Varieté III). Lo que Valéry no percibía es que el análisis de las "figuras" estaba mucho menos abandonado de lo que él quiso creer. Una de las labores de la estilística moderna consiste, precisamente, en el análisis de las figuras, sentido de las palabras, significado de las estructuras lingüísticas.

A partir del siglo xvir, empieza a imponerse una visión del mundo histórica, dinámica y móvil. Cassirer ha observado que la diferencia entre la "razón" de los "racionalistas" y la razón de la Época de las Luces está en que la primera es razón inmóvil mientras que la segunda es razón en acto, razón activa. Nadie declara y proclama el sentido dinámico de la razón como Hegel en la Ciencia de la lógica. La razón analítica ha sido sustituida por la razón 
dialéctica. Así, racionalismo e historicismo empiezan por pactar, aun cuando lleguen a una ruptura acaso insalvable en buena parte de la filosofía poshegeliana.

De manera semejante evoluciona el concepto de estilo y, por consiguiente, de esta ciencia del estilo que es la estilística. Un estilo que busca esencias fijas y cuasi platónicas -el "rien n'est Beau que le Vrai" de Boileauviene a ser sustituido por una idea dinámica y vital (del romanticismo al surrealismo, del realismo al expresionismo) de lo que se suele llamar "estilo". Si "el estilo es el hombre" (Buffon) y si el hombre es un ser mudable y dinámico, el estilo será fluidez, cambio, emotividad: historia. Y la estilística - también la lingüística- de fines del siglo xvir y del siglo xix serán también estilísticas de la fluidez y del cambio; estilísticas historicistas. El estilo es así la manifestación de la subjetividad. Ya D'Alembert escribía que el estilo es la manifestación del "genio o el talento de quien escribe o de quien habla" (Mélanges littéraires) y Chauteaubriand: "el estilo no se aprende; es un don del cielo, un talento" (Mémoires d'Outre Tombe). En nuestro siglo dirá Maurice Blondel: "tener estilo es no escribir sino aquello que se piensa y aquello que uno siente en uno mismo" (Carnets intimes). Así, se vuelve difícil hablar del estilo; cada estilo es el reflejo de una persona concreta y en cierto sentido habrá tantos estilos como haya "personas", "talentos", subjetividades diversas.

Lo que sucede con el concepto del estilo individual sucede igualmente con el estilo y las lenguas de los pueblos. Las lenguas, vivas, dinámicas, se desarrollan, crecen, proliferan. Las lenguas tienen una historia; su historia. Tal la opinión de lingüistas como W. von Humbold o como Grimm.

Sin embargo, no toda la estilística del siglo pasado o del nuestro es estilística historicista. Una de las formas de la estilística - la que nace de la lingüística general de Ferdinand de Saussure, se ocupará más de la lengua que de la palabra, más de este todo organizado y sincrónico que es la lengua que de esta fluidez diacrónica que son las palabras. De esta tendencia lingüística surgirá la esencia de Bailly y habremos de verla reaparecer, con un vigor inusitado, en las escuelas formalistas y estructurales de nuestro siglo. La estilística dinámica - también la más cercana a la crítica literaria- se inaugura con las obras de Karl Vossler y Leo Spitzer. ${ }^{8}$

Spitzer hurga en el sentido de la literatura a partir de la obra misma. Su actitud proviene - así lo ha declarado el propio Spitzer- de una reacción contra la enseñanza que él mismo había recibido en las clases de Mayer. Lübcke. Escribe irónicamente Spitzer: "Para cada forma francesa Mayer-Lübcke citaba el antiguo portugués, el macedonio, el rumano moderno, el germánico, el celta; pero, ¿dónde quedaba en esta enseñanza mi francés sensual, irónico, disciplinado por sus mil años de historia? Se quedaba en

$8 \mathrm{El}$ punto de vista formal se discute más adelante. 
la puerta mientras hablábamos de su lengua; en realidad, el francés no era la lengua de los franceses sino un conglomerado de evoluciones sin relación entre sí, aisladas, anecdóticas y carentes de significado" (Linguistics and Literary History). Influido por el romanticismo y, más hondamente, por Bergson y Croce, Leo Spitzer parte de la intuición de la obra para así tratar de encontrar su significación dinámica. Lectura en parte sintomática, lectura construida sobre una simpatía inicial, la que Spitzer llevó magistralmente a cabo es, por así decirlo, una lectura oblicua. Lo que en una obra es revelador, es su alejamiento de las normas y de las leyes del estilo "objetivo". Es decir, lo que importa en el análisis concreto, son los rasgos, los matices, las variaciones que introduce en el lenguaje un espíritu creador.

Prodigio de claridad y de sensibilidad analítica es este libro de doble vertiente teórica y práctica que Dámaso Alonso publicó con el título de Poesía española, Ensayo de métodos y limites estilisticos (1952).

El libro intercala ideas muy precisas sobre el sentido de la estilística y análisis exactísimos sobre Garcilaso, Fray Luis de León, San Juan de la Cruz, Góngora, Lope de Vega, la modernidad de la poesía española de los Siglos de Oro. Limitémonos aquí a las ideas sobre la estilística que Dámaso Alonso describe en cinco partes.

Empieza Dámaso Alonso por distinguir entre dos conceptos clave: el de significante y el de significado. La distinción se encuentra en la obra de De Saussure y constituye una de las fuentes de discusión en la estilística formal y estructural que habremos de analizar más adelante.

El significante es, en términos de De Saussure, una imagen acústica; el significado es conceptual. Así, un signo eś un significado doblado de significante.

Dámaso Alonso altera de raíz la distinción saussuriana. El significante es para Dámaso Alonso tanto el sonido como la imagen acústica (es decir, es, a la vez, físico y psíquico). Distinción todavía de poca monta. Lo que señala una clara diferencia entre las ideas de De Saussure y las de Dámaso Alonso es que el primero entiende el significado como significado conceptual mientras que, para Dámaso Alonso, "es siempre complejo y, dentro de él, se pueden distinguir una serie de significados parciales". Así, el significado es un "complejo de significados parciales" y el lenguaje, "un inmenso complejo en el que se refleja la complejidad psíquica del hombre". El lenguaje es así siempre lenguaje de un sujeto concreto y expresa no sólo conceptos sino sentimientos, emociones, imágenes. Por otra parte, el significante es "todo lo que en el habla modifica leve o grandemente nuestra intuición del significado... Ese acento es un significante parcial legítimo; el poema, un significante enormemente complejo". Finalmente, Dámaso Alonso rechaza la noción saussuriana de arbitrariedad. "En poesía hay siempre una vinculación motivada entre significado y significante. Y si distinguimos entre forma inte- 
rior y forma exterior, la crítica literaria será crítica de la segunda, es decir, pasará del significante al significado." 9

El proyecto saussuriano ha sido prácticamente invertido. Lo que importa para Dámaso Alonso es la palabra viva, el poema organizado, el significado espiritual del poema. ${ }^{10}$

En la segunda parte de Poesía española donde se trata del "conocimiento de la obra poética", se dice que "el lector es el artista donde se completa la relación poética". El lector, el multiplicado lector de un mismo poema, es el re-creador del poema, el lector participante y participado.11 Pero, además del lector normal, está este lector especializado que es el crítico. La actividad del crítico no es puramente receptiva. Como la del poeta, es expresiva. Intuitivo como el creador, el crítico tiene que alcanzar lo "esencial" del poema y expresarlo bajo la forma "condensada de su impresión".

Lector, crítico: dos niveles de lectura. En un tercer nivel, la lectura de la ciencia literaria. El hecho es que la obra poética plantea una serie de problemas que atañen tanto al poema como a la obra de arte, a la crítica como a la filosofía. La crítica no puede dar respuestas a estos problemas que están más allá de la intuición. Debe ceder el paso a estas "ciencias en deseo" que son las ciencias humanas. Entre estas ciencias en proyecto está la estilística literaria. ${ }^{12}$ La estilística, más que una ciencia es un "avance" hacia la ciencia. Avance, por lo demás, proyectivo, ya que la estilística es "la ciencia del habla", es decir, de la movilización momentánea y creativa de los depósitos idiomáticos. La estilística, individualizante y concretadora, no puede generalizar sin peligros. De ahí que no deban establecerse tipologías de pretensiones universales con la intención de resolver los problemas que plantean la lectura de un texto o la contemplación de un cuadro. Si tratamos de establecer semejantes tipologías "por las mallas se nos escaparía el pescado".

No duda Dámaso Alonso del valor de ciertas clasificaciones establecidas inductivamente. Duda de su valor para juzgar -intuición dirigida a una intuición- la obra de arte, el poema. La estilística literaria puede pretender estudiar la multiplicidad de significantes ("sucesión temporal de sonidos") y el significado ("concepto espiritual"). Y ello conjuntamente, ya que los significantes alteran nuestra vida espiritual cualitativamente y no cuantitativamente. El crítico estilístico debe establecer interrelaciones de dependencia entre los significantes (orden físico-temporal) y el significado (orden

9 Dámaso Alonso señala que una critica completa seria tanto interior como exterior. La primera es demasiado compleja en el estado de nuestros conocimientos.

10 La idea de la poesía - y la crítica - como "palabra viva" se encuentra, a principios de siglo, en el Elogio de la palabra de Joan Margall y no es ajena al pensamiento de Antonio Machado.

11 Una idea similar habrá de encontrarse en el "practical criticism" de A. I. Richards.

12 Dámaso Alonso preveía ya con certeza el conflicto, y la confusión, que ha creado la estilística estructural, estilística que difícilmente, habremos de verlo, puede llegar al sentido de la obra concreta. 
espiritual). Idealmente, el crítico, si agotase el significado del poeta, llega. ría mediante una intuición totalizadora, a la intuición totalizadora del poeta.

\section{Critica formal. Critica estructural}

El formalismo no es nuevo en el estudio del lenguaje o del conocimiento humanos. La Retórica y la Poética de Aristóteles muestran rasgos de análisis estructural. El análisis de estructuras de pensamiento $-\mathrm{y}$ del lenguajeno es ajeno al tomismo y es el meollo de las críticas kantianas. En lingüística, lo hemos visto, buena parte del análisis estructural se inspira en De Saussure. Pero ni toda lingüística implica una crítica ni todo formalismo es estructural. Inútil, por apartado de nuestro tema, considerar aquí las diversas formas del formalismo cuyo conocimiento, por lo demás, queda y debe quedar en manos de especialistas. Tanto la hipótesis saussuriana -propiamente lingüística - como las tentativas inductivo-deductivas por establecer una combinatoria universal en los Prolegómenos a una teoria del lenguaje de Hjemslev, tanto la gramática generativa de Chomsky como la fonología estructural de la escuela de Praga quedan fuera de este examen. Sin duda existen contactos claros entre la lingüística formal, la crítica y la obra literaria. ¿No hacia notar Roman Jakobson que buena parte del formalismo deriva del formalismo literario ruso? También es cierto que formalismo y estructuralismo han influido poderosamente en años recientes a la crítica literaria. Me limitaré aquí a dos tendencias: la que quiere fundamentar una poética formal (Polivanov, Roubaud) y la que pretende criticar la obra de arte por métodos estructurales (Barthes).

Evgeny Polivanov fue una de las figuras principales en torno a la revista Poetika. En 1920, Polivanov escribió un texto todavía muy valioso: El principio fonético común a toda técnica poética.13 En él, Polivanov se ocupa únicamente de la forma y considera, por el momento, que el contenido semántico es indiferente: Existen, por lo demás, formas poéticas carentes de significado como la poesía "transmental" que Polivanov considera forma muy pura de la expresión poética. La hipótesis formal de Polivanov consiste en afirmar que dentro de los tipos básicos de versificación (métrica, silábica, tónica), los procedimientos técnicos y poéticos se reducen a los hechos de "reanudación". No se trata aquí de reanudación de palabras que se repiten, sino de reanudación fonética. Naturalmente, la reanudación fonética elegida en cada lengua dependerá de la estructura de la lengua. No piensa Polivanov que las condiciones fonéticas sean únicas y exclusivas (existen condiciones sociales, económicas, históricas para entender el poema); piensa, sin embargo, que son hechos observables y aislables.

13 Tanto el texto de Polivanov como el que se cita en seguida de Roubaud aparecen en Change, 6, Paris, 1970. 
Más ambicioso acaso en su formalismo, y también más sistemático, es Jácques Roubaud. En Algunas tesis sobre la poética, Roubaud se inspira en Chomsky y en Halle (The Soundpattern of English) y propone una poética fundada en la linguística generativa. No pretende Roubaud, como lo habían pretendido Bierwish y Bezzel (La gramática de la poesía) distinguir la gramática de la poética para aislar el hecho poético y establecer "escalas de poeticidad" enunciadoras de juicios de valor. En Algunas tesis sobre la poética, Jacques Roubaud define la "poética" en los términos siguientes: "Entenderemos aquí por poética el estudio de las relaciones entre la literatura y el lenguaje". No se trata de una definición axiomática; se trata más bien de una hipótesis de trabajo. La literatura, que la poética estudia, habla del lenguaje y, por lo tanto, "no dice sino lo que dice" al hablar del lenguaje. Pero, y sin contradicción, la literatura que habla del lenguaje habla también de otra cosa que el lenguaje. En este punto literatura y lingüística se distinguen si nos damos cuenta de que la segunda se limita a hablar del lenguaje. Así, "la literatura habla del lenguaje al hablar de otra cosa que el lenguaje y no habla de otra cosa sino hablando del lenguaje: indisolublemente". A partir de estas ideas generales, Roubaud propone una serie de definiciones y de axiomas.

Las definiciones centrales son estas: 1) Def: "Para toda definición propuesta de la literatura existe un contraejemplo"; Def': sea un rasgo (positivo o negativo) afirmado universalmente de la literatura; es posible escribir un texto literario que lo niegue (por ejemplo: es afirmable y negable la proposición: "no hay poesía sin imágenes").

La literatura, en su variedad formal, es, además, código "de un lenguaje y del lenguaje". De lo cual se sigue que la literatura es no sólo el código de una lengua sino el código de todos los lenguajes y memoria de ellos. ${ }^{14}$ En otras palabras: la literatura entra en una doble relación con el lenguaje: la literatura compuesta en un lenguaje habla de la lengua en este lenguaje. Tal es el axioma fundamental que propone Roubaud. De él se derivan cuatro "axiomas de fundación": I) el lenguaje no existe sin la literatura; 2) toda lengua tiene una literatura; 3) la literatura es una condición de existencia del lenguaje; 4) la literatura de una lengua es condición de existencia de esta lengua.

Jacques Roubaud ofrece un ejemplo de aplicación de sus hipótesis y axiomas en un proyecto de teoría del verso libre, cuando llega a la conclusión de que el único rasgo formal que lo caracteriza es el hecho de "ir aparte", corte fundamental del verso que deben respetar tanto la tipografía como la lectura silenciosa o dicha. Además, en el verso libre, el verso constituye una "frase".

14 Entiéndase aqui por código un sistema de definiciones; por memoria: la conservación de leyes formales, rítmicas, fraseológicas, discursivas, etc. 
Una vez más, en la hipótesis de Roubaud, como en la de Polivanov, cuentan poco los significados semánticos; lo que cuenta es la estructura formal del poema y de su análisis en la "poética".

Interesantes como son las contribuciones de Polivanov o de Jacques Roubaud, pierden de vista el poema vivo. ¿Juzgar la casa que se habita por un sistema de planos?; jjuzgar los planos por un sistema de relaciones cuantitativas? La estilística formal $y$, en general, el formalismo, suelen quedarse en lo que Dámaso Alonso, al hablar de Bailly, llamó alguna vez "una estilistica sin estilo".

Más claramente estructural es el método de Roland Barthes, tanto en sus primeras obras (principalmente El grado cero de la escritura), como en sus escritos críticos y, recientemente, sus textos ligados a la sociología.

Lo más original que ha escrito Barthes, desde el punto de vista teórico, está en El grado cero de la escritura. ¿Qué es la "escritura"? Barthes empieza por hacernos ver aquello que la escritura no es. La escritura no debe confundirse con la lengua; "más acá" de la literatura, la lengua es un límite; límite distante y horizonte del cual "el escritor no entresaca nada". Pero si la escritura no es la lengua, tampoco es el estilo. Éste existe "más allá" de la literatura y constituye una suerte de "necesidad que liga el humor del escritor con su lengua". "El estilo es propiamente de orden germinativo, es la transformación de un humor." ¿En qué consiste la escritura? Barthes, que empieza por definirla como una función ("la relación entre la creación y la sociedad"), añade que la escritura es voluntaria y responde a una intención precisa. Si el estilo es un humor subjetivo y la lengua un límite objetivo - "límite inicial de lo posible"-, la escritura es una función electiva. El estilo, en efecto, es el hombre; precisamente por ello es inútil tratar de analizarlo. La escritura, en cambio, se ofrece a los ojos del crítico. ${ }^{15}$

En un texto reciente (El análisis retórico, Literatura y sociedad, Barcelona, 1969), Roland Barthes distingue la literatura como institución de la literatura como "obra-objeto". Concebida como obra-objeto, la literatura tiene dos aspectos: uno en que lo literario se mezcla con lo no literario; otro, específicamente literario que Jakobson llamó "poética". En términos ya clásicos de Alfonso Reyes habría que distinguir entre la función ancilar y la función propiamente literaria de la literatura.

A Io que Jakobson Ilamó "poética", Barthes lo llama "retórica". Su pregunta, muy central, es ésta: saber "si es posible una confrontación entre sociedad y retórica y en qué condiciones”. La retórica que estudia Barthes es

15 Barthes distingue varios tipos de escritura: clásica, valorativa y a veces condenatoria (como en la literatura marxista cuando usa palabras como "desviacionista", "revisionista", etc.), comprometida. Prescindo aquí de otros aspectos, de orden valorativo, de importancia indudable. Entre ellos la descripción-valoración de la poesia, descripción que termina con un análisis muy agudo acerca del "hambre de palabras" de una poesía que, a partir de Mallarmé, se ha vuelto a la vez hermosa y "terriblemente inhumana". 
una retórica estructural-informacional. Desde esta perspectiva, la literatura es un mensaje, un mensaje informacional. Pero a diferencia de los mensajes comunes y corrientes, la literatura constituye un "sistema de información costoso". La información que nos da la literatura no es directa ni es descriptiva: suele ser elíptica y oblicua. ${ }^{16}$ De ahí que la información literaria y especialmente poética, puedan surgir de la vida social sin que sea dable probar y comprobar, punto por punto, la relación entre literatura y sociedad. Para que esta relación se mostrara habría que buscar relaciones analógicas entre códigos distintos y simultáneos (el de las letras, el de la sociedad). Así: "el análisis retórico debería depender directamente no de la sociología propiamente dicha sino más bien de esa sociológica, o sociología de las formas de clasificación que postulaban ya Dürkheim y Mauss".17

Roland Barthes con la nueva noción de escritura intenta evitar el formalismo de una suerte de lingüística poética y un sociologismo del cual trataremos más adelante en este examen. Su obra teórica sigue, sin embargo, en la línea formal. De ella, y en general de todo formalismo, habría que decir lo que Pierre Francastel ha dicho con relación al estudio formal del arte: "La obra de arte es lo posible y lo probable; nunca, lo seguro" (Arte, forma, en Estructuralismo y estética, Buenos Aires, 1969).

\section{El "New Criticism"}

El apelativo genérico de "nueva crítica" proviene de un libro de John Crowe Ramson precisamente titulado The New Criticism. Bajo este rubro, algo vago y general, suelen comprenderse críticos tan varios como Yvor Winters, Van Wyck Brooks, R. P. Blackmur, Kenneth Burke, William Empson, A. I. Richards. Entre ellos hay que destacar la obra verdaderamente monumental de Richards.

Impresiona la obra de Richards por su variedad. El significado del significado, escrito en colaboración con C. K. Ogden, fundó en buena medida la semántica moderna; en 1922, Richards, nuevamente en colaboración con Odgen y con James Wood, publica The Foundation of Aesthetics donde el equilibrio estético se funda en la armonía cenestésica. Ya desde sus primeras obras, algunas premisas quedan establecidas. Richards se ocupará ante todo del problema de la relación autor-lector y su método será principalmente psicológico, si bien Richards no se suma a ninguna tendencia psicológica exclusiva. Se suceden los libros de Richards: Principles of Literary Criticism (1924), Science and Poetry (1926), Practical Criticism (1929), Coleridge on Imagination (1932). Además, interesado por la comunicación en el nivel

¿16 El escándalo que la poesía representa ante la lógica y el sentido común ha sido espléndidamente analizado por Octavio $\mathrm{Paz}$ en $E l$ arco y la lira y Las peras del olmo.

17 Sociología de las formas que ha tenido una definida y clara influencia en la obra de Lévi-Strauss. 
educativo, dedica esfuerzos considerables al desarrollo del inglés básico e, in. teresado por el pensamiento oriental, escribe Mencius on Mind (1932). ¿Qué tienen en común libros tan diversos en estilo y género? Principalmente tratar de explicarse la relación entre el creador y el lector mediante lo que Richards llama, diversamente, "interpretación" o "retórica" y, sobre todo, por medio de la "interpretación múltiple" de los textos.

Inspirándose en John Stuart Mill, Richards distingue entre un lenguaje preciso y exacto (lenguaje denotativo de las ciencias en términos de Mill y lenguaje simbólico en términos de Richards) y lenguaje poético (connotativo; según Mill, evocador o emotivo según Richards). En alguna ocasión, principalmente cuando se dedica al inglés básico, Richards piensa, con Ogden, que un mínimo de palabras es suficiente para expresar cualquier pensamiento. Pero cuando se ocupa de literatura, Richards, que no cree en las lecturas absolutamente correctas de un poema, cree que existen múltiples lecturas entre las cuales habrá buenas y malas. En los Principles of Literary Criticism, Richards rechaza el punto de vista "místico" en relación con el arte y afirma que no existe un modo especial de pensamiento que pueda llamarse pensamiento estético. La experiencia del poema no es, en esencia, distinta de otras experiencias emotivas. Teñido de utilitarismo, Richards escribe: "Todo lo que satisfaga una apetencia sin implicar la frustración de una apetencia igual o superior, es valioso". Así, "la organización que desperdicie menos posibilidades humanas es, en suma, la mejor".

¿Cómo leer un poema? Para leerlo bien hay que recordar cuáles son los factores que entran en la experiencia emotiva del creador y del lector. Richards destaca las siguientes: sensaciones visuales que produce la palabra escrita; las imágenes muy cercanas, asociadas a estas sensaciones; las emocio nes; las actitudes volitivo-afectivas; las imágenes relativamente libres; las referencias a otros pensamientos. Leer un poema no es así hablar de la Belleza sino referirse a un refinado y complejo lenguaje emotivo. La crítica tendrá por objeto describir el valor psicológico - acto de juicio e "inspección directa" - que la obra produce en el lector. La crítica no es así una mera técnica, si por técnica entendemos la mera descripción de un objeto sin tener en cuenta el valor del objeto. Podría objetarse, claro está, que el criterio que emplea Richards es demasiado amplio y que, a) se aplica a cualquier lectura, y no solamente a la lectura de un poema; b) que cualquier lectura es válịda puesto que el poema, vuelto a crear por el lector, sólo puede valer según la medida de cada lector particular. A lo primero Richards contestaría afirmativamente aun cuando añadiría que la lectura de un poema se distingue por su grado de complejidad; a lo segundo que existen buenos y malos lectores y buenas y malas lecturas.

I. A. Richards; y no es ésta una de sus menores originalidades, aplicó su idea de la crítica al escribir Practical Criticism. El libro, extraordinario en 
su género, reproduce varias lecturas hechas por personas cultas. El resultado es alarmante. Valga un ejemplo. Entre los lectores de Richards, go afirman que John Donne es un gran poeta, 42 que no les gusta, 28 que les es indiferente. En cambio, un poeta tan menor como J. D. Pellow merece 54 aprobaciones, 31 rechazos y 15 juicios indiferentes. ${ }^{18}$ ¿Qué se propone Richards con su "técnica de laboratorio" y de "lectura múltiple"? Ver cómo realmente leen los lectores. ¿Qué resultados obtiene? Saber que el público culto en general lee mal. ¿Qué propone? Mejorar la lectura y, por lo tanto, la comunicación. De hecho el mejor resultado de este libro excepcional es el gusto que el propio Richards muestra en sus lecturas. Mismo gusto, misma penetración, misma "inspección directa" bien orientada que muestra el propio Richards en sus lecturas a Coleridge $o$ a Mencio..$^{19}$

\section{Critica sociológica}

Ninguna escuela niega del todo la importancia de la sociedad en la critica literaria. Algunos críticos han llegado a pensar, sin embargo, que el marco social es la garantía prácticamente única de una buena crítica. Así lo creyó Taine cuando asentó que el arte depende de la raza, el medio y el momento. Nadie, sin embargo, ha insistido tanto sobre las condiciones sociales de la obra de arte como los críticos marxistas.

Los avatares de la crítica marxista siguen de cerca las "aventuras de la dialéctica" y aun a veces, cuando la crítica es obra de políticos, las ondulaciones de la táctica.20 El primer problema que plantea la crítica marxista es la ausencia de crítica literaria -0 , en general, de estética- en las obras de Marx y Engels. Ciertamente han podido reunirse un buen número de juicios de gusto escritos por uno y otro. Pero estos juicios no pasan de ser juicios personales, relativamente comunes entre los lectores cultos del siglo pasado. Ha escrito muy exactamente Adolfo Sánchez Vázquez: "Los textos de Marx y Engels sobre cuestiones estéticas y literarias, publicados por primera vez en 1933 por Mijáil Lifshits, pese al papel que han desempeñado en la destrucción de una estética sociológica vulgar e ideologizante, no constituyen todavía una estética marxista y ni siquiera la columna vertebral de ella".21 De hecho el problema concreto de la relación entre las letras y las artes y la sociedad se plantea, para el marxismo, a partir de la revolución rusa. $Y$ ello en varios momentos, matices y movimientos: afirmación revo-

18 Naturalmente, los lectores desconocian al autor de los textos que leían y comentaban.

19 Otro de los grandes libros que aplica la lectura múltiple y la noción de ambigüedad es Seven Types of Ambiguity de Empson.

20 Dos aspectos de actitud táctica: la aceptación de la obra de Picasso y, ya en el plano de la política interior rusa, el uso del realismo socialista.

21 Estética y marxismo, 1, 19. Esta antología, publicada por Era, México, 197o, contiene, en dos tomos, material indispensable para entender la critica marxista y buena parte de su evolución. 
lucionaria de los poetas y pintores futuristas y constructivistas, más tarde tachados de burgueses y decadentes; ataques al futurismo y al constructivismo considerados como formalistas por parte de Lenin, Bujarin e incluso de este espíritu más libre en cuestiones de arte que fue Lunacharsky; formulaciones más abiertas y, por así llamarlas, liberales, en pensadores y escritores de los años 30 (Brecht, Lukacs, Gramsci, Christopher Caudwell); breve liberación, en la URSS, después de la muerte de Stalin - lo que se llamó el "deshielo"-; reanudación de la crítica cerrada en la URSS después de los casos Pasternak y, recientemente, Daniel o Solshenitsyn; apertura más decidida en el marxismo de Occidente en los años de 50 a 7o: Kosik, Della Volpe, Sánchez Vázquez, Kolakowski, Macherey, Goldman.

La actitud de Lenin hacia el arte fue ambigua. Indudablemente veia el arte como político y, además, como político convencido del valor indiscutible de sus principios. Lenin no gustó de las formas que tomaba, dentro o fuera de Rusia, el arte contemporáneo. Tradicionalista en arte y en letras, revolucionario en política, Lenin quiso que se creara un arte proletario y. no dudó en recomendar medidas tácticas. Está, entre otras, en un texto Sobre la politica del partido en el terreno de la literatura (véase Sánchez Vázquez, Estética y marxismo, II): “Con respeto a los 'compañeros de viaje' se ha de tener en cuenta: I) su diferenciación; 2) la importancia de muchos de ellos como 'especialistas' calificados en literatura; 3) la existencia de vacilaciones en esta capa de escritores. La directriz general debe ser en este caso tratar̂los con tactó y cuidado, es decir, con enfoque que asegure todas las condiciones necesarias para su paso con la mayor rapidez posible al lado de la ideología comunista." Juicio político que Lenin traduce también en juicio didáctico è imperativo misionero. La idea que Lenin tiene del arte; y de. la crítica, es otra. Dispone la ruptura con los "prejuicios señoriales" y propone un arte "comprensible para millones de personas". La idea era ya en sí discutible; ¿no son asequibles los grandes escritores de Occidente?; ¿no pueden gustarlos millones de personas?; ¿es seguro que el arte deba "entenderse", es decir, que su función sea didáctico-cognoscitiva?

La crítica de Bujarín contra el formalismo ruso pretende distinguir tajante y claramente entre la reducción de la literatura a forma -condenable a la luz de un hipotético realismo socialista- y el estudio de los elementos formales del lenguaje y del arte, "necesario y útil en gradö sumo" (Estética y marxismo, I). Ya Lunacharsky había definido las "tareas de la crítica marxista" en 1928. El criterio de Lunacharsky era muy sencillo: "lo que contribuye al desarrollo de y a la victoria de la causa proletaria es bueno, y lo que perjudica a ella es malo" (Ibidem, I). No niega Lunacharsky la importancia de la forma pero busca, en el futuro, la posibilidad de un mayor encuentro entre la forma y el contenido.

Hay que decirlo, la actitud de Bujarín como la de Lunacharsky fue 
todavía relativamente liberal. No así, como es sabido, la práctica de las letras y la crítica-impositiva que se desarrolló y sigue desarrollándose dentro de la URSS.

Es posible que la obra más completa escrita por un crítico marxista sea la de Georg Lukacs. Su obra es vastísima: son conocidos sus análisis de Goethe, Hegel, Balzac, Mann, los idealistas alemanes, su amplísima obra de Estética. Pero acaso la mayor originalidad de. Lukacs haya consistido en tratar de precisar un nuevo tipo de realismo que llama "realismo crítico", en abierta oposición al "realismo socialista". Las ideas de Lukacs, bien resumidas en Significado actual del realismo crítico, mezclan virtudes y defectos. Las virtudes principales están en los análisis concretos de autores concretos. Pero la teoria de Lukacs es endeble y es más hipotética que real. En efecto, el realismo que describe Lukacs es un realismo solamente posible.

Lukacs quiere ser imparcial y afirma que es tan grave que el Occidente vea en la literatura de vanguardia la única expresión literaria valiosa como pensar, con la URSS, que la literatura occidental es toda ella "monolítica". Lukacs distingue, en efecto, dentro de la literatura de Occidente, dos tendencias: el realismo crítico -especialmente representado por la obra de Thomas Mann-y el "anti-realismo" que Lukacs no vacila en calificar de "decadente". Estas dos tendencias responden a dos visiones del mundo y, sobre todo, a dos maneras de concebir al hombre. La primera concibe al hombre en su actividad teórico-práctica, operatoria, social, ligada a" la lucha de cláses y al dominio creciente de la naturaleza; la segunda es idealista y concibe al hombre y al artista como desligados de-la.sociedad. De quienes tienen el primer concepto del hombre dirá Lukacs que poseen "perspectivâ"; de los segụndos, que carecen de ella. Dos motivos subrayan esta carencia: el subjetivismo y el alegorismo. Entiende Lukacs por subjetivismo la "riqueza ilusoria" de una "subjetividad abstracta". Tal, a su parecer los casos de Joyce, Kafka o Eliot. La idea de Lukacs está lejos de ser clarạ. Y está lejos de serlo porque si Ulises o Finnegan's Wake parten de experiencias subjetivas, no por ello dejan de partir de la vida concretísima de Dublin a principios de nuestro siglo. Por otra parte; chasta qué punto dejan de ser subjetivas las experiencias iniciales de Balzac o de Mann? Tampoco se entiende claramente el rechazo del alegorismo. Para Lukacs la alegoría consiste en "sustituir el tipo concreto por la particularidad abstracta". Así, la alegoria es negadora de la sociedad y de la historia. En este punto las objeciones históricas son de peso: o se acepta la alegoría y se acepta a Platón, Dante, Petrarca, Calderón, buena parte del romanticismo y del simbolismo, o se niega y se niega gran parte de la literatura de Occidente y de Oriente. Es claro que Lukacs podría contestar que existen dos tipos de alegoria: una que se refiere a la trascendencia y otra que permanece en la inmanencia. Pero la distinción es a la vez tajante y oscura porque, en el fondo, Lukacs parece negar a ambas. Para 
él, la alegoría trascendente - por ejemplo, la de la pintura de Giotto- es solamente decorativa. Pero, ¿cómo pensar que las alegorías de Giotto son meramente decorativas? $O$ jes que se trata únicamente de negar a Joyce y a Kafka? En este caso no se entiende por qué el realismo está obligado a negar obras que realmente representan situaciones reales.

Cuando Lukacs habla del realismo socialista señala muy claramente sus defectos: romanticismo, sentimentalismo, dogmatismo, estereotipia. A este realismo Lukacs opone el realismo crítico y, en términos kantianos, lo llama la "idea reguladora" de las artes. Pero una idea reguladora carece de realidad y el realismo crítico de Lukacs es, en última instancia, o bien un juicio de gusto - preferencia por Balzac o por Thomas Mann- o bien una hipótesis que permanece en el hipotético reino de lo posible.

Muchas han sido las tentativas - algunas verdaderamente interesantespor abrir la crítica marxista hacia una aceptación más auténtica, y menos polémico-valorativa, del hecho literario: Sánchez Vázquez, Della Volpe, Kosik, Kolakowski. No es claro que, a pesar de claros esfuerzos, haya podido romperse con los juicios de valor que la política impone; como tampoco es claro, en última instancia, que la sociedad determine, de manera prácticamente exclusiva, la obra de arte y la obra del crítico. ${ }^{22}$

\section{Algunos puntos a modo de conclusión}

Tres puntos, en conjunto, que no puedo presentar sino en forma esquemática; tres puntos, a través de los cuales, puede traslucirse una idea de la crítica y una idea de las relaciones necesarias entre poema, crítica, filosofía.

I) En la crítica como en la filosofía me parece válida la sugerencia de Leibniz: la crítica suele ser auténtica - por no hablar aquí de verdad- en aquello que afirma e inauténtica en aquello que niega. Cualquier punto de vista tomado como el punto de vista tiende a tomar la parte por el todo y a re-

22 En Estética y marxismo, libro al cual hay que remitir para el estudio del tema, se ponen de manifiesto actitudes de clara renovación. Una de las discusiones a mi modo de ver centrales es la de la permanencia o impermanencia de la obra de arte. ¿Hasta qué punto ver en la estructura socioeconómica la condición de obras que perduran más allá de una estructura dada? Por otro lado, autores como Glucksman han sugerido que el estudio de la obra literaria debe ser estructural y dinámico. Glucksman intenta señalar la existencia de estructuras globales básicas (la historia literaria, la biografía del autor, el grupo social al cual el autor estudiado pertenece). Pero estas estructuras dependen de una triple hipótesis: la de una racionalidad no cartesiana; la de la tendencia de cada grupo social a "lograr una coherencia global"; la de una tendencia que supere la estructura social en que se vive. Las ideas de Glucksman, interesantes, son también reductivistas en cuanto limitan el significado a las condiciones sociales. Frente a Glucksman me parece exacta la idea de Barthes, arriba expuesta y según la cual es acaso posible relacionar por analogia el hecho social y el hecho literario sin que sea posible, ni deseable, establecer entre ambos relaciones de causa a efecto. 
ducir lo que es mirada a un solo y mero golpe de vista que se pretende totalizador. Ante las diversas escuelas críticas es pertinente criticar aquello que afirman con dogmatismo o niegan con el mismo dogmatismo. Vimos cómo la crítica psicoanalitica tiende a ser crítica sintomática. Sin embargo, el psicaanálisis ha influido a algunos de los grandes críticos modernos aun cuando a su vez algunos aspectos del psicoanálisis -fundamentalmente la noción de inconsciente- estuvieran ya presentes tanto en la poesía como en las concepciones del mundo que surgen del romanticismo. El encuentro entre critica y psicoanálisis suele resultar fecundo cuando el crítico es principalmente artista y alcanza, por emplear las palabras de Richards, una inspección inmediata de la obra. Por lo que toca a la ciencia literaria, sus virtudes de claridad no siempre anulan sus defectos de generalidad. De ella podria decirse lo que Whitehead suele decir de las filosofías mecanicistas: incurren en la falacia de la "concretez desplazada", falacia que consiste en tomar lo abstracto por lo concreto y en pensar que lo abstracto es lo real.

La fenomenología propiamente dicha no ha dado lugar a una crítica literaria. Por un lado los críticos que se inician como fenomenólogos tienden a convertirse en críticos formalistas (Ingarten); por otro, una serie de críticos, entre ellos Reyes, que realizan auténtica crítica literaria con claros métodos descriptivos no pueden ser calificados, con todo rigor, de fenomenólogos. Entre el psicoanálisis y la fenomenología ha surgido una modalidad crítica -acaso irrepetible - que es importante precisamente porque es personal y personalizante: la de Bachelard.

La crítica estilística cuando es estructural se convierte más en lingüística que en crítica literaria y adolece de las mismas fallas de abstracción, la mismà falacia de la "concretez desplazada". de que adolece tanto la crítica formalista como la ciencia literaria. Cuando la crítica estilística es diacrónica e intersubjetiva - Spitzer, Dámáso. Alonso- suele ser gran critiça; suele ser también muy exacta en la crítica que hace de la crítica formal-conceptual pero es ya menos exacta - aun cuando su camino sea bueno- al hablar de significados intuitivos. Intuición: palabra necesạria pero también, vaga; palabra que merecería una aclaración y acotación más precisa.

El "New Criticism" intenta, científicamente, 'esta inspección- inmediata que Dámaso Alonso llamaba intuición. Pero los críticos anglosajones que practican la "nueva crítica" - ya por cierto no tan nueva- distan mucho de formar una escuela unitaria. Su aportación debe juzgarse por sus obras críticas concretas y aun Richards, cuya hipótesis de una lectura múltiple es realmente fructífera, vale más por sus análisis críticos que por la teoría psicológico-semántica quie defiende.

De la crítica sociológica, y principalmente en estas últimas décadas, marxista, es bueno recordar que nos hace conscientes de la necesidad de volver a los hechos sociales; es igualmente bueno ver, con toda nitidez, que sus 
tentativas, más o menos radicales, de reducir la literatura a las leyes sociales se prestan a dogmatismo y yerro.

En última instancia, una escuela crítica vale por los críticos que la constituyen y, sin duda, valdrá más en cuanto sea menos "escuela" y más disciplina; menos una serie de principios abstractos y dogmáticos que una forma metódica suficientemente flexible para que el poema - la obra que se estudia - no sea reducida, sino comprendida.

Lo cual no significa que la crítica sea ni deba ser ajena a toda teoría. $\mathrm{Y}$ esto conduce a mi segundo punto.

2) Que la crítica no es ajena a la teoría lo muestran, muy principalmente, los filósofos mismos. Algunas de las mejores páginas críticas han sido escritas por filósofos: de Platón a Heidegger, de Aristóteles a Whitehead, de Hegel a Merleau-Ponty. Y ello no fundamentalmente porque el hecho literario y principalmente poético sea del interés del filósofo bajo la especie de un interés externo; sino; radicalmente, porque con gran frecuencia el hecho poético es parte integrante de la filosofía. Dos ejemplos. En la filosofía de Hegel, no es vano recordarlo, el arte es una de las formas más altas del conocimiento, antepenúltima realización del Espíritu Absoluto solamente sobrepasado por la religión y la filosofía; en Heidegger, la visión de los poetas completa - "pastores", como son, "del ser"- la más limitada y conceptual visión de los filósofos. El poeta ve lo que el filósofo anuncia.

3) Generalizo. Si por una parte los filósofos son críticos y tienden a serlo más cuando la obra poética que analizan es parte de su filosofía, los críticos son, implícita o explícitamente, filósofos. El crítico tiene una concepción del mundo y lo que expresa, en su concepción del mundo, es tanto la intención de la obra analizada como su propia intención en cuanto ésta revela su manera de ver el mundo. El crítico ve la obra del poeta. Doble visión complementaria. Porque si es cierto que el poeta revela el mundo bajo su forma de verlo, el crítico ve, a través de sí mismo y a través de la obra del poeta, su propio mundo. ¿Mundos coincidentes? No es probable que lo sean ni es probable que lo sean jamás del todo. Porque el poeta viene a enriquecer el mundo y el crítico, si entiende el significado del poema, verá en él tanto lo que en él puso el poeta como lo que en él pone el espíritu del crítico. No hay aquí absolutos ni hay significaciones meramente unívocas. Pero es que la univocidad, que puede prestarse a ciencia, no se presta a ser arte. El arte es, multiplicadamente, variedad de perspectivas hacia el mundo. El crítico, que interpreta la obra de arte —si aquí puede hablarse de interpretar y no más bien de ver y mirar - no ve necesariamente lo mismo que vio el poeta. El crítico, como lector atento, viene a añadir su propio matiz, su propia diferencia participante, al poema. Así, la creación artística y la recreación de 
ella en la lectura o la contemplación vienen a representar un mismo juego del ver y el mirar; el juego de los matices que conducen a entendernos acaso más por las diferencias que por las semejanzas. La lógica pura identifica. Es una forma de ver y entender. La otra forma del ver y del entender es la que nos hace participar - tal la labor del poeta, tal la del artista-, de tal manera que la obra viva como obra viviente que es. En efecto, el Quijote no es el mismo después de que Cervantes leyó la primera parte y escribió la segunda, ni es el mismo después de las múltiples lecturas diferenciales y enriquecedoras que aportan, entre otros, Unamuno, Ortega, Borges, Foucault.

Ver y entender: acaso no sea otro el sentido de la palabra intuición. De ser así, la labor del filósofo - sabio aquí más que especialista- como la labor del poeta son formas del ver y del entender. En este mismo sentido, la tarea del lector, el oficio del crítico, son tarea y oficio de participación: que es entendimiento enriquecido. Los significados que busca la crítica -que busca el poeta, que busca el artista- no son, en efecto, significados lógicos. Son significados emotivos, imaginativos, significados variables. Así, la crítica es y deberá ser intersubjetiva y, como tal, mucho más labor de un crítico concreto, que de una "escuela" o un sistema.

RAMÓN XIRAU

Universidad Nacional Autónoma de MÉxico 